\title{
In silico docking analysis of CCL28 (C-C motif chemokine ligand 28) and astragalin as the potential inhibitor of
} rheumatoid arthritis [version 1; peer review: 1 approved, 1 approved with reservations]

Sadaf Noor, Syeda Tahira Qousain, Syed Aun Muhammad (D)

Institute of Molecular Biology and Biotechnology, Bahauddin Zakariya University, Multan, Punjab, 60800, Pakistan

V1 First published: 20 Mar 2019, 8:313

https://doi.org/10.12688/f1000research.18541.1

Latest published: 20 Mar 2019, 8:313

https://doi.org/10.12688/f1000research.18541.1

\section{Abstract}

Background: Rheumatoid arthritis is an inflammatory and chronic disease of the joints affecting $1 \%$ of the world's population. Women are three times more likely to be affected than men. Many drugs are being used for the treatment of rheumatoid arthritis but they often have severe side effects. C-C motif chemokine ligand 28 (CCL28) recruits leukocytes and other proinflammatory factors to the site of joint inflammation. The purpose of the present research is the computational evaluation of astragalin, a natural flavonoid extracted from black tea, as an inhibitor of CCL28 by in silico docking.

Methods: The three-dimensional structure of CCL28 to act as a molecular target was obtained from the Protein Data Bank (PDB ID: 6 CWS). The quality of the CCL28 structure was assessed using Phyre ${ }^{2}$ and Molecular Operating Environment (MOE) software was used for binding affinity analysis. Astragalin served as a ligand for docking and naproxen, a known drug for rheumatoid arthritis, was used as a standard for comparison.

Results: In molecular docking, astragalin showed significant binding affinity with the CCL28 target molecule, with a binding energy of -5.40 $\mathrm{kcal} / \mathrm{mol}$, in comparison with naproxen which has a binding energy of $-4.87 \mathrm{kcal} / \mathrm{mol}$. Astragalin has strong binding affinity for CCL28 as compared to standard naproxen.

Conclusion: This study revealed that astragalin could have the potential to serve as an inhibitor of CCL28 for the treatment of rheumatoid arthritis.

\section{Keywords}

Rheumatoid arthritis, CCL28 inhibition, Molecular docking, Astragalin, Binding affinity

\section{Open Peer Review \\ Approval Status ? \\ 12 \\ version 1 ? \\ 20 Mar 2019 view view \\ 1. Ihsan UI Haq, Quaid-i-Azam University, \\ Islamabad, Pakistan \\ 2. Sagarika Biswas, Institute of Genomics and \\ Integrative Biology, New Delhi, India \\ Any reports and responses or comments on the article can be found at the end of the article.}




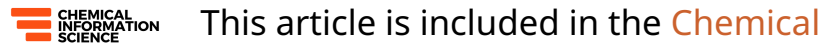

Information Science gateway.

Corresponding author: Syed Aun Muhammad (aunmuhammad78@yahoo.com)

Author roles: Noor S: Investigation, Methodology, Writing - Original Draft Preparation, Writing - Review \& Editing; Qousain ST:

Methodology, Writing - Original Draft Preparation; Muhammad SA: Conceptualization, Formal Analysis, Supervision

Competing interests: No competing interests were disclosed.

Grant information: The author(s) declared that no grants were involved in supporting this work.

Copyright: @ 2019 Noor S et al. This is an open access article distributed under the terms of the Creative Commons Attribution License, which permits unrestricted use, distribution, and reproduction in any medium, provided the original work is properly cited.

How to cite this article: Noor S, Qousain ST and Muhammad SA. In silico docking analysis of CCL28 (C-C motif chemokine ligand 28) and astragalin as the potential inhibitor of rheumatoid arthritis [version 1; peer review: 1 approved, 1 approved with reservations] F1000Research 2019, 8:313 https://doi.org/10.12688/f1000research.18541.1

First published: 20 Mar 2019, 8:313 https://doi.org/10.12688/f1000research.18541.1 


\section{Introduction}

Rheumatoid arthritis (RA) is an autoimmune inflammatory disease of synovial joints ${ }^{1}$. The prevalence of RA is about $1 \%$ worldwide and women are three times more likely to be affected than men. The onset of RA is mostly seen in people aged 30-50 but can occur at any age ${ }^{2,3}$. In the past two decades, research has advanced understanding of RA pathogenesis which has revolutionized RA treatment and led to the development of new therapeutic agents ${ }^{4}$. Non-steroidal anti-inflammatory drugs (NSAIDs) and disease-modifying anti-rheumatic drugs (DMARDs) are groups of drugs commonly used to control and alter the progression of $\mathrm{RA}^{4,5}$. However, these medications cannot completely cure RA, are expensive and have some notable side effects. Therefore, the development of new therapeutics for RA with fewer side effects is required.

Astragalin (Kaempferol 3-O-beta-D-glucoside) is a flavonoid found in black tea, alcoholic beverages such as red wine and Cuscuta plants. Preliminary studies have shown it has potential pharmacological characteristics such as anti-inflammatory and antioxidant properties ${ }^{6,7}$. Computational analysis is an important technique for determining the potential of astragalin in inhibiting C-C motif chemokine ligand 28 (CCL28). Virtual screening tools provide an easy way to identify therapeutic targets suitable for multiple ligands ${ }^{8}$.

CCL28, a mucosa-associated epithelial chemokine, is found in the epithelial cells of many tissues such as the lungs, guts and salivary glands. Studies have reported the involvement of CCL28 in RA angiogenesis, a process that occurs early in RA pathogenesis 9 . RA angiogenesis is fostered by the interaction of pro-inflammatory cytokines and chemokines. The ligation of CCL28 to its receptor CCR10 is involved in B- and T-cell trafficking in RA pathogenesis ${ }^{10}$.

The ability of astragalin to bind and inhibit CCL28 has not yet been reported. Therefore, in this paper we will describe the potential inhibition of the CCL28 target by an astragalin ligand using computational and bioinformatics tools.

\section{Methods}

Target protein structure

The three-dimensional crystal structure of the target protein CCL28 (PDB ID: 6CWS) ${ }^{11}$ was downloaded from the Protein Data Bank $^{12}$ in PDB format using a similar method to that carried out by Esther et al. ${ }^{13}$

\section{Preparation of ligand}

The two-dimensional chemical structure of astragalin was accessed from the PubChem database (PubChem CID: 5282102) and drawn using Accelrys Draw 4.1 software $^{14}$ with default parameters. The resulting MOL file of the ligand was converted into PDB format by Accelrys Discovery Studio 4.1 software $^{15}$ using default parameters. The chemical structure of astragalin is shown in Figure 1. We used naproxen as standard drug which is being used against arthritis. The chemical structure of this molecule was taken from the PubChem database (PubChem CID: 156391).<smiles>O=c1c(OC2OC(O)[C@H](OP)C(OP)[C@H]2O[Hg])c(-c2ccc(O)cc2)oc2cc(O)c(O)cc12</smiles>

Figure 1. Chemical structure of astragalin accessed from PubChem (ID: 5282102).

\section{Optimization of target and ligand}

PDB coordinates of target and ligand proteins were optimized by energy minimization, 3D protonation and stable conformation parameters of Molecular Operating Environment (MOE) software $^{16}$ (version 2014.0901) and files were saved in MDB format.

\section{Quality estimation of target protein}

The quality of the CCL28 predicted protein structure was estimated using the Phyre $^{2}$ (Protein Homology/analogY Recognition Engine, version 2.0) online web server ${ }^{17}$. The ProQ2 quality assessment and Ramachandran plot was applied for identifying the structural conformation of the proteins using the default parameters of the tool.

\section{Binding site analysis}

We computed and analysed the binding sites of target protein using the default parameters of the MOE software ${ }^{16}$.

\section{Molecular docking analysis}

A computational ligand-target docking approach was used to determine structural complexes of CCL28 with astragalin in order to understand the structural basis of these protein targets specificity. Finally, docking was carried out by MOE based on RMSD and E-score. The energy of the interaction of these derivatives with the protein targets is assigned "grid point". At each step of the simulation, the energy of the interaction of ligand and protein was evaluated using atomic affinity potentials computed on a grid. Molecular docking was performed to analyse the binding of the astragalin ligand with the active sites of the CCL28 target protein. The optimized ligand was docked with the target using MOE software ${ }^{16}$ with default parameters as described by Esther et $_{\text {al. }}{ }^{13}$

\section{Results}

Quality estimation of predicted CCL28 protein structure

The quality of the CCL28 predicted protein structure was estimated by the Phyre $^{2}$ web server ${ }^{17}$. Phyre $^{2}$ provided a 3D structure of the target protein and the dimensions of the 3D structure in $\AA$ were $\mathrm{X}=48.506, \mathrm{Y}=53.506$ and $\mathrm{Z}=38.552$. Analysis of the secondary structure of the target protein provided by Phyre ${ }^{2}$ 
revealed high confidence in the predicted structure, indicated by red regions in Figure 2, suggesting that the protein structure quality is high. The sequence profile graph shows that $\mathrm{M}$ residues are highly favourable, $\mathrm{L}$ and $\mathrm{V}$ residues are moderately favourable and remaining residues are less favourable. The ProQ2 quality assessment showed the quality of protein target and could be considered as "good" model indicating less mutation sites in the protein structure (Figure 3). The Ramachandran plot shows that approximately $98 \%$ amino acid residues of the target protein model exist in the most favoured region whereas $<2 \%$ exist in the disallowed region. This Ramachandran plot representing the backbone conformation of CCL28 amino acid residues is shown in Figure 4.
Binding site analysis and molecular docking

Binding sites of the target protein were analysed using MOE software $^{16}$. Analysis revealed that His 99 and Thr 101 residues were present in a pocket of the target protein. The spatial orientation of the astragalin ligand in the binding pocket of the target is shown in Figure 5. In silico molecular docking using MOE software ${ }^{16}$ resulted in the successful docking of target CCL28 with the astragalin ligand. The binding energy of astragalin with CCL28 is $-5.40 \mathrm{kcal} / \mathrm{mol}$, as compared to standard naproxen which has a binding energy of $-4.87 \mathrm{kcal} / \mathrm{mol}$. A comparison of the binding energies and root-mean-square deviation (RMSD) values of astragalin and standard naproxen with the CCL28 target is shown in Table 1 and Table 2
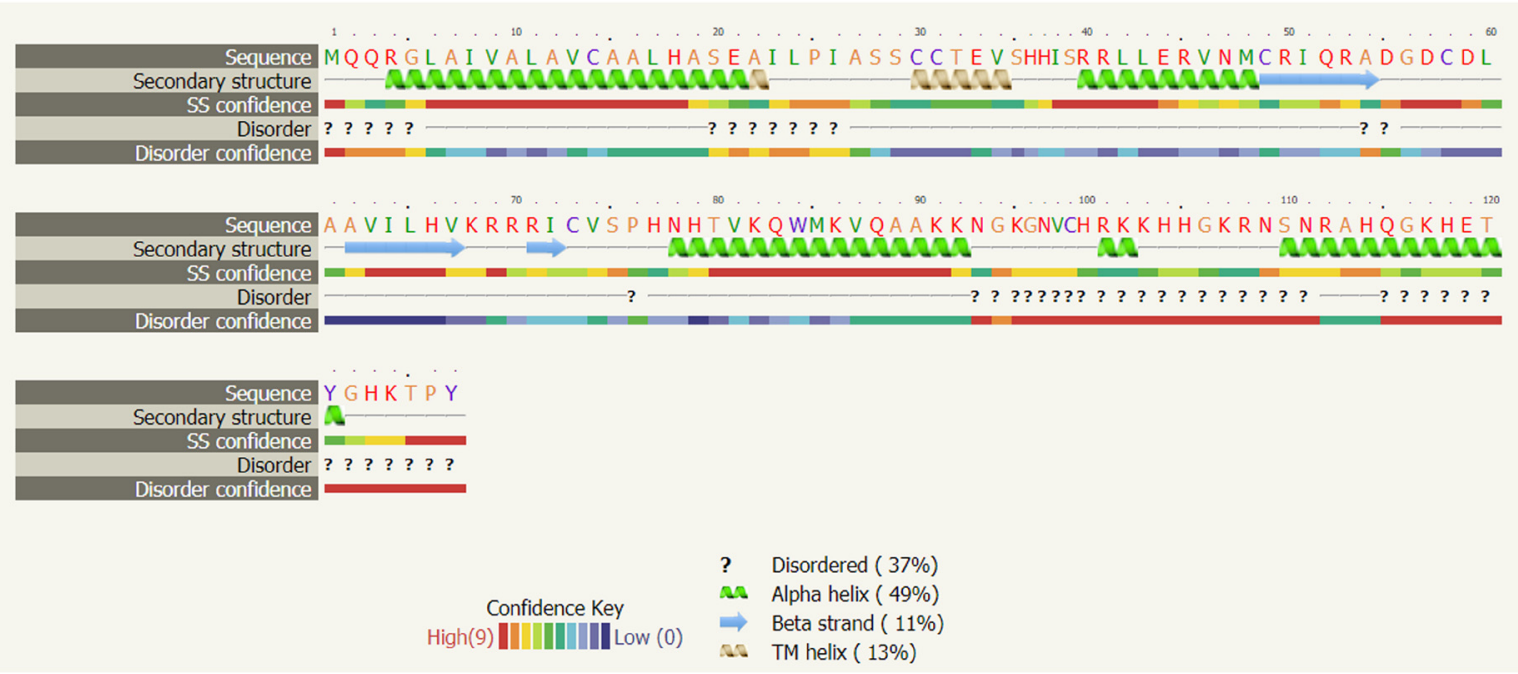

Figure 2. The CCL28 was modelled using the Phyre2 server. The sequence alignment of protein molecule shows high confidence, indicated by red colour, while blue indicates low confidence. $49 \%$ of the structure is in alpha helices, $11 \%$ is in beta-strands and $13 \%$ is in transmembrane helices.

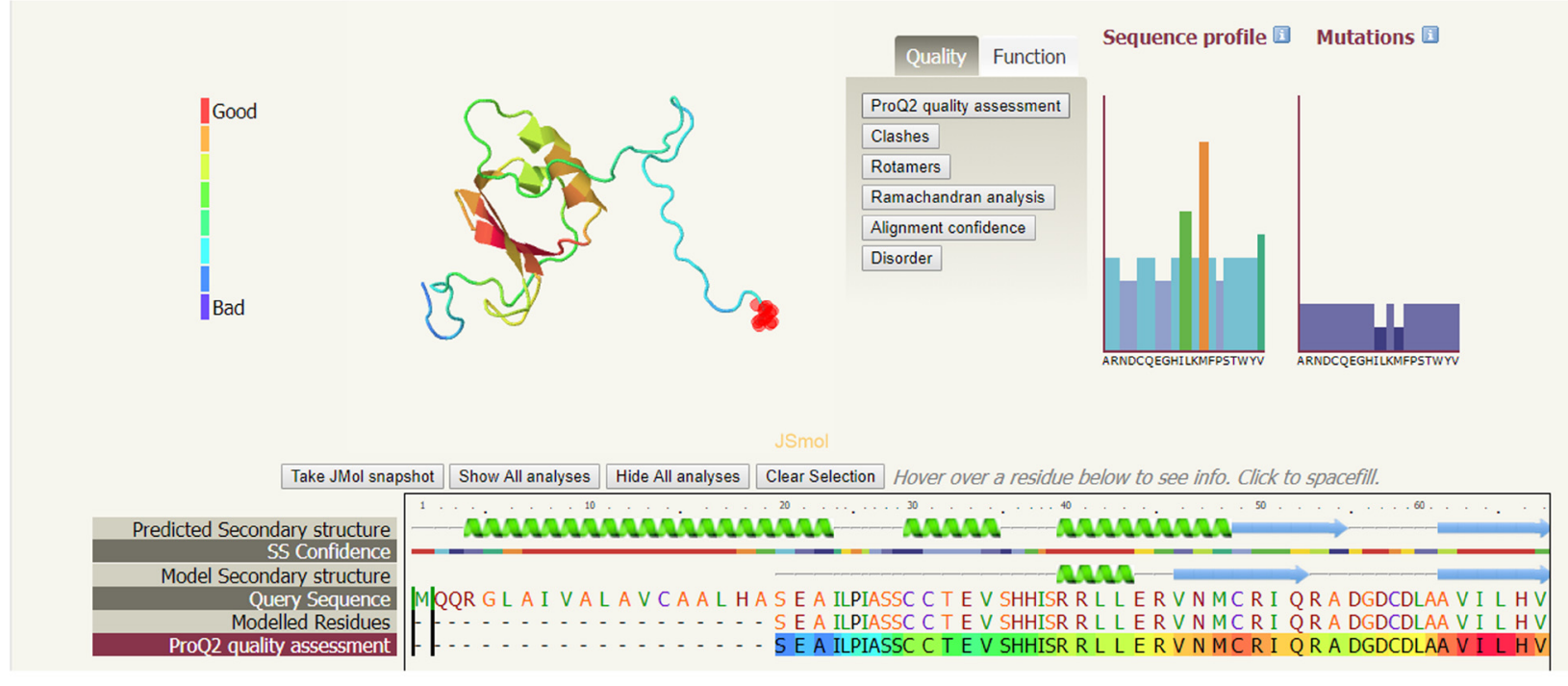

Figure 3. The quality of the CCL28 model was estimated by ProQ2 of the Phyre2 server. Red colour indicates "Good" regions while blue represents "Bad" regions of the structure. The quality of model indicated the minimal disordered region (shown by broken lines). 


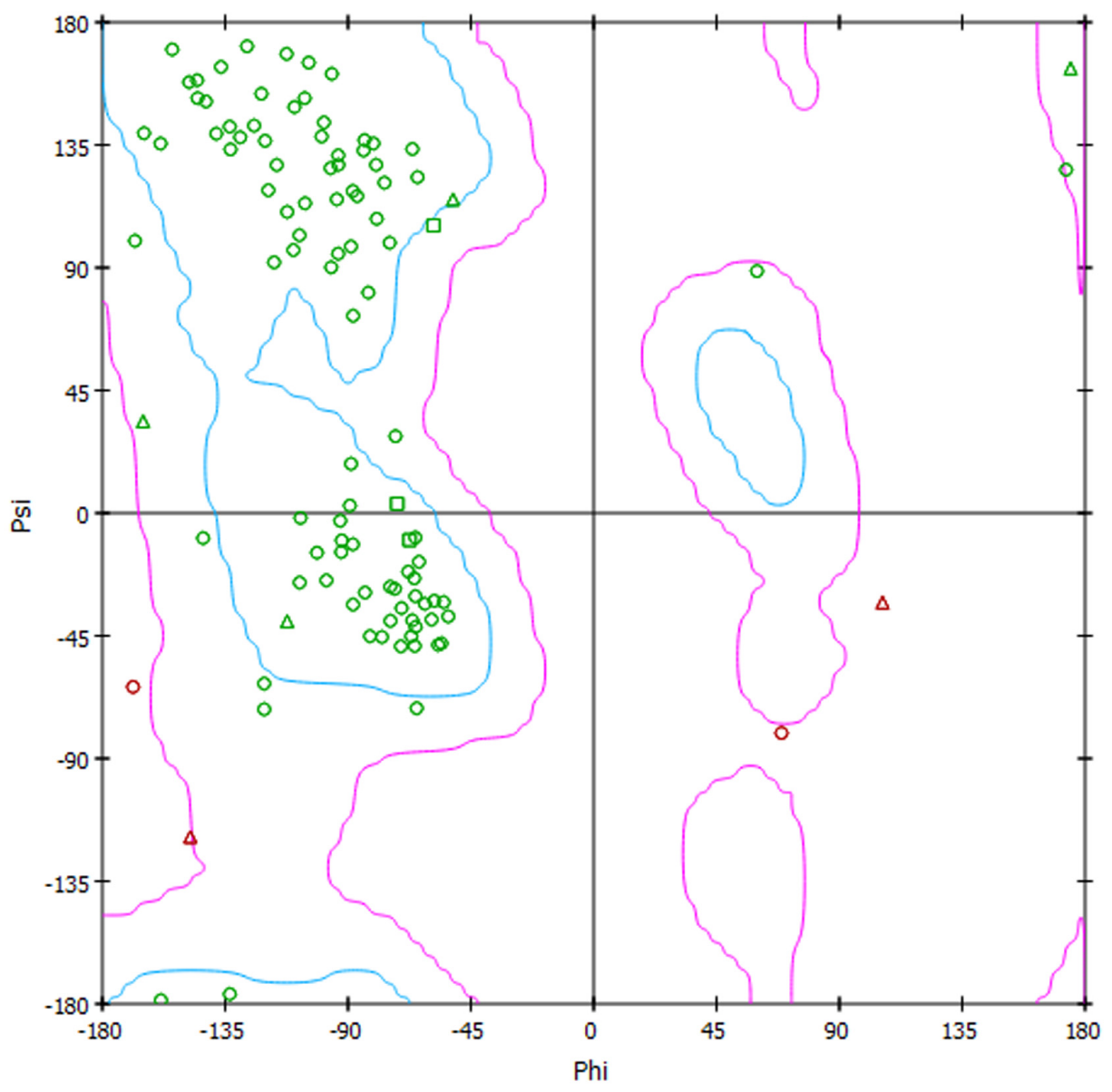

Figure 4. The Ramachandran plot of the CCL28 protein target constructed by ProQ2 indicated whether the amino acid residues occur in the "favoured region" or "disallowed region" of the plot. For a "good" protein model there must be $\geq 90 \%$ amino acid residues in the most favoured region or $<2 \%$ in the disallowed region of the plot.

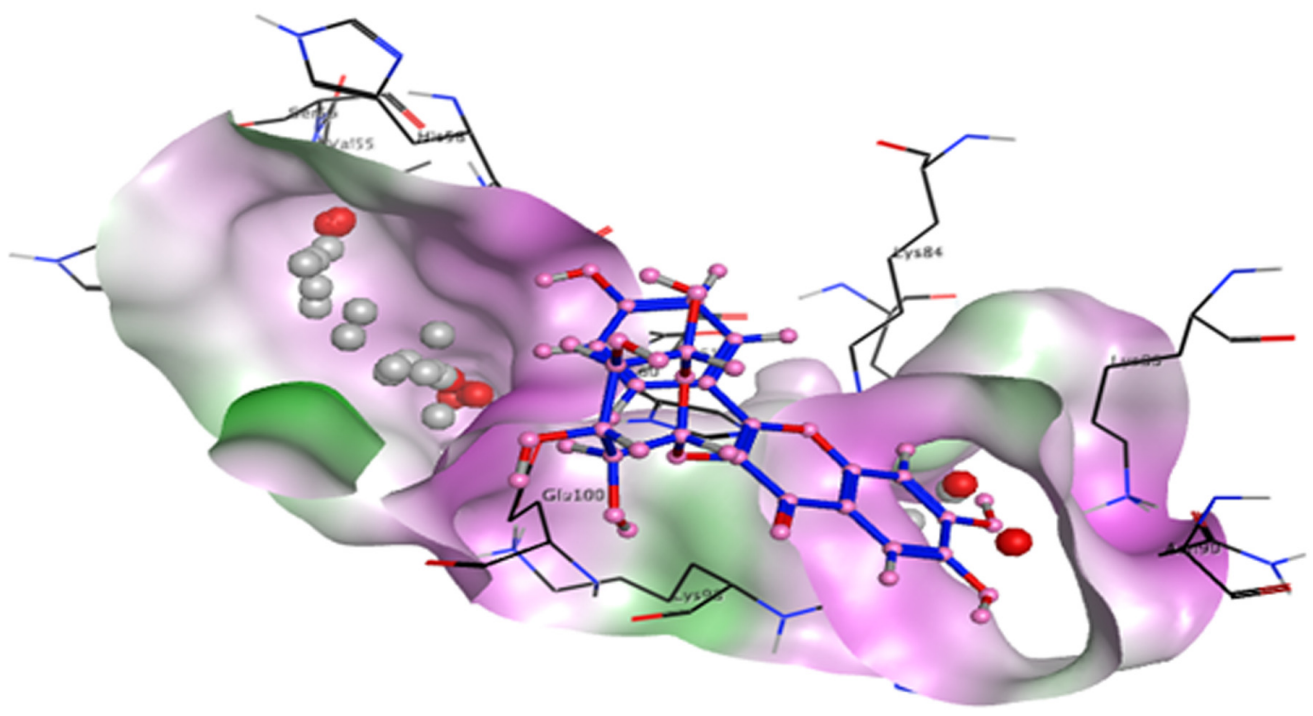

Figure 5. Confirmation and pose of molecular docking interaction of astragalin as ligand molecule with CCL28 as target protein. 
respectively. Results show that astragalin has strong binding affinity for the CCL28 target molecule as compared to naproxen. The ligand interaction module of $\mathrm{MOE}^{16}$ was used to view ligand interactions. Figure 6 shows astragalin interacting with CCL28 via hydrogen bonding with the His 99 and Thr 101 residues.

\section{Discussion}

The CCL28 protein is involved in the angiogenesis of rheumatoid arthritis as it recruits leukocytes to the site of joint inflammation. Inhibition of the CCL28 protein blocks the migration of leukocytes and other proinflammatory factors and this serves as a promising target for arthritis ${ }^{18}$.

Methotrexate and leflunomide are DMARDs used for rheumatoid arthritis treatment. In a few patients, serious liver damage due to methotrexate has been observed. Similarly, leflunomide also exhibits certain side effects ${ }^{19}$. These side effects have increased the need for the development of safe alternative, treatment approaches. Current research is focused on the development of bioactive molecules from natural resources which don't have side effects $^{20}$. Astragalin isolated from the leaves of black and green tea possesses potential therapeutic effects including anti-inflammatory, antioxidant and anticarcinogenic activities. It may have the ability to inhibit the production of inflammatory mediators such as IL-1b, IL-6 and TNF-alpha ${ }^{19}$.

Astragalin acts as an inhibitor and prevents the binding of CCL28 to its receptor CCR10 which is a primary step for the recruitment of leukocytes and formation of blood vessels inside inflamed joints of RA patients ${ }^{21}$.

\begin{tabular}{|c|c|c|c|c|c|}
\hline Serial No. & MOL & MSEQ & S & RMSD & E SCORE \\
\hline 1 & Astragalin-CCL28 & 1 & -5.4045 & 2.6406 & -5.4045 \\
\hline 2 & Astragalin-CCL29 & 1 & -4.9543 & 2.271 & -4.9543 \\
\hline 3 & Astragalin-CCL30 & 1 & -4.7815 & 2.7907 & -4.7815 \\
\hline 4 & Astragalin-CCL31 & 1 & -4.625 & 2.7101 & -4.625 \\
\hline 5 & Astragalin-CCL32 & 1 & -4.5687 & 2.6752 & -4.5687 \\
\hline 6 & Astragalin-CCL33 & 1 & -4.4539 & 2.604 & -4.4539 \\
\hline 7 & Astragalin-CCL34 & 1 & -4.4806 & 3.4983 & -4.4806 \\
\hline 8 & Astragalin-CCL35 & 1 & -0.9169 & 1.3223 & -0.9169 \\
\hline 9 & Astragalin-CCL36 & 1 & -0.047 & 2.4669 & -0.047 \\
\hline 10 & Astragalin-CCL37 & 1 & 0.8654 & 1.6814 & 0.8654 \\
\hline
\end{tabular}

Table 2. Binding Energy (E SCORE), RMSD (root mean square deviation), MSEQ (molecule sequence number) and S (scoring function) values obtained during docking analysis of naproxen as a standard drug and CCL28 as a target protein.

\begin{tabular}{|c|c|c|c|c|c|}
\hline Serial No. & MOL & MSEQ & S & RMSD & E_SCORE \\
\hline $\mathbf{1}$ & Naproxen-CCL28 & 1 & -4.873 & 1.9432 & -4.873 \\
\hline $\mathbf{2}$ & Naproxen-CCL28 & 1 & -4.794 & 4.5019 & -4.784 \\
\hline $\mathbf{3}$ & Naproxen-CCL28 & 1 & -4.478 & 7.0793 & -4.478 \\
\hline $\mathbf{4}$ & Naproxen-CCL28 & 1 & -4.334 & 2.1122 & -4.334 \\
\hline $\mathbf{5}$ & Naproxen-CCL28 & 1 & -4.253 & 4.3536 & -4.253 \\
\hline $\mathbf{6}$ & Naproxen-CCL28 & 1 & -4.050 & 2.1431 & -4.050 \\
\hline $\mathbf{7}$ & Naproxen-CCL28 & 1 & -4.023 & 0.9265 & -4.023 \\
\hline $\mathbf{8}$ & Naproxen-CCL28 & 1 & -3.902 & 3.5261 & -3.902 \\
\hline $\mathbf{9}$ & Naproxen-CCL28 & 1 & -3.688 & 4.0819 & -3.688 \\
\hline $\mathbf{1 0}$ & Naproxen-CCL28 & 1 & -3.652 & 2.3819 & -3.652 \\
\hline
\end{tabular}




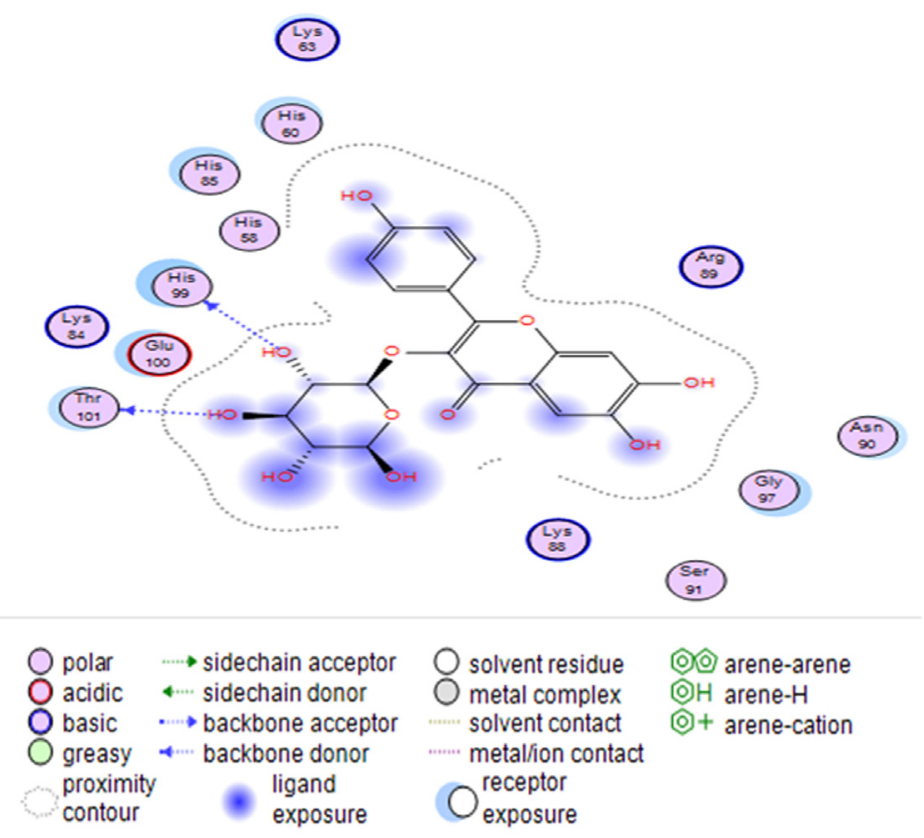

Figure 6. Binding site atoms of CCL28 residues around ligand showed interaction of His99 and Thr101 amino acid residues of CCL28 with ligand atoms (carbon and oxygen atoms).

In silico docking studies of astragalin with CCL28 were carried out using MOE software ${ }^{16}$. Lowest binding energy and root mean square values (RMSD) from docking studies indicate a strong interaction between ligand and target. In silico molecular docking showed successful binding of CCL28 with the astragalin ligand. The binding energy of astragalin with CCL28 is $-5.40 \mathrm{kcal} / \mathrm{mol}$, a lower binding energy than that of naproxen with CCL28 which is $4.87 \mathrm{kcal} / \mathrm{mol}$. These docking results suggest that astragalin can act as a potential inhibitor for CCL28.

\section{Conclusion}

Molecular docking results of astragalin with CCL28 showed that this ligand has strong binding affinity for CCL28. Therefore, astragalin may act as an important inhibitor of CCL28 to treat rheumatoid arthritis in the future.

\section{Data availability}

Underlying data

Structure of CCL28 from Protein Data Bank, Accession number 6CWS: https://identifiers.org/pdb/6CWS.

Structure of naproxen from PubChem Database, Accession number 156391: https://identifiers.org/pubchem.compound/156391

Structure of astragalin from PubChem Database, Accession number 5282102: https://identifiers.org/pubchem.compound/5282102

Grant information

The author(s) declared that no grants were involved in supporting this work.
1. Barhamain AS, Magliah RF, Shaheen MH, et al:: The journey of rheumatoid arthritis patients: a review of reported lag times from the onset of symptoms. Open Access Rheumatol. 2017; 9(1): 139-50. Open Access Rheumatol. 2017; 9(1): 139-50.
PubMed Abstract | Publisher Full Text | Free Full Text

2. Brennan-Olsen SL, Cook S, Leech MT, et al:: Prevalence of arthritis according to age, sex and socioeconomic status in six low and middle income countries: analysis of data from the World Health Organization study on global AGEing and adult health (SAGE) Wave 1. BMC Musculoskelet Disord. 2017; 18(1): 271. PubMed Abstract | Publisher Full Text | Free Full Text

3. Rudan I, Sidhu S, Papana A, et al.: Prevalence of rheumatoid arthritis in lowand middle-income countries: A systematic review and analysis. $J$ Glob Health. 2015; 5(1): 010409.

PubMed Abstract | Free Full Text
4. Hussain W, Noorwali A, Janoudi N, et al.: From Symptoms to Diagnosis: An Observational Study of the Journey of Rheumatoid Arthritis Patients in Saudi Arabia. Oman Med J. 2016; 31(1): 29-34. PubMed Abstract | Publisher Full Text | Free Full Text

5. Kahlenberg JM, Fox DA: Advances in the medical treatment of rheumatoid arthritis. Hand Clin. 2011; 27(1): 11-20. PubMed Abstract | Publisher Full Text | Free Full Text

6. Riaz A, Rasul A, Hussain G, et al.: Astragalin: A Bioactive Phytochemical with Potential Therapeutic Activities. Adv Pharmacol Sci. 2018; 2018(1): 9794625. PubMed Abstract | Publisher Full Text | Free Full Text

7. Cho IH, Choi YJ, Gong JH, et al:: Astragalin inhibits autophagy-associated airway epithelial fibrosis. Respir Res. 2015; 16(1): 51. PubMed Abstract | Publisher Full Text | Free Full Text 
8. Zhou W, Cai JF, Yuan F, et al.: In silico targeting of interleukin-6 by natural compounds. Bangladesh J Pharmacol. 2014; 9(3): 371-76. Publisher Full Text

9. Lazarus NH, Kunkel EJ, Johnston B, et al:: A common mucosal chemokine (mucosae-associated epithelial chemokine/CCL28) selectively attracts IgA plasmablasts. J Immunol. 2003; 170(7): 3799-805. PubMed Abstract | Publisher Full Text

10. Chen Z, Kim SJ, Essani $A B$, et al:: Characterising the expression and function of CCL28 and its corresponding receptor, CCR10, in RA pathogenesis. Ann Rheum Dis. 2015; 74(10): 1898-906. PubMed Abstract | Publisher Full Text | Free Full Text

11. Thomas MA, He J, Peterson FC, et al: The Solution Structure of CCL28 Reveals Structural Lability that Does Not Constrain Antifungal Activity. J Mol Biol. 2018; 430(18 Pt B): 3266-3282.

PubMed Abstract | Publisher Full Text | Free Full Text

12. Berman HM, Westbrook J, Feng Z, et al:: The Protein Data Bank. Nucleic Acids Research. 2000; 28: 235-242.

PubMed Abstract | Publisher Full Text | Free Full Text

13. Esther MYJ, Subramaniyan V, Kumar AP, et al:: Molecular docking, ADMET analysis and dynamics approach to potent natural inhibitors against sex hormone binding globulin in male infertility. Pharmacogn J. 2017; 9(6s): 35-43. Publisher Full Text

14. Dassault Systèmes BIOVIA: Accelrys Draw, version 4.1. San Diego: Dassault
Systèmes, 2012

Reference Source

15. Dassault Systèmes BIOVIA: Discovery Studio Modeling Environment, Release 2017. San Diego: Dassault Systèmes, 2016

16. Molecular Operating Environment (MOE), 2013.08; Chemical Computing Group ULC, 1010 Sherbooke St. West, Suite \#910, Montreal, QC, Canada, H3A 2R7, 2019.

17. Kelley LA, Mezulis S, Yates CM, et al:: The Phyre2 web portal for protein modeling, prediction and analysis. Nat Protoc. 2015; 10(6): 845-58. PubMed Abstract | Publisher Full Text | Free Full Text

18. Szekanecz Z, Koch AE: Successes and failures of chemokine-pathway targeting in rheumatoid arthritis. Nat Rev Rheumatol. 2016; 12(1): 5-13. PubMed Abstract | Publisher Full Text

19. Bartold PM, Marshall RI, Haynes DR: Periodontitis and rheumatoid arthritis: a review. J Periodontol. 2005; 76(11 Suppl): 2066-74. PubMed Abstract | Publisher Full Text

20. Carvalho CdS, Andrade LEC, Keusseyan SP, et al.: Study of advanced rheumatoid arthritis. Rev Bras Eng Bioméd. 2014; 30(1): 54-63. Publisher Full Text

21. Jia Q, Wang T, Wang $X$, et al:: Astragalin Suppresses Inflammatory Response and Bone Destruction in Mice With Collagen-Induced Arthritis and in Human Fibroblast-Like Synoviocytes. Front Pharmacol. 2019; 10(1): 94-06. PubMed Abstract | Publisher Full Text | Free Full Text 


\section{Open Peer Review}

\section{Current Peer Review Status:}

\section{Version 1}

Reviewer Report 09 February 2021

https://doi.org/10.5256/f1000research.20293.r78162

(C) 2021 Biswas S. This is an open access peer review report distributed under the terms of the Creative Commons Attribution License, which permits unrestricted use, distribution, and reproduction in any medium, provided the original work is properly cited.

\section{Sagarika Biswas}

Council of Industrial Research (CSIR), Institute of Genomics and Integrative Biology, New Delhi, Delhi, India

\section{In the Introduction section:}

Information about RA angiogenesis and early RA pathogenesis may be provided.

What is the chemical formula of astragalin and what are its biological function?

What are the diseases in which the effect of astragalin is already reported?

The information of other ligands that are reported to be inhibited by astragalin and hence can be potential inhibitors of other inflammatory diseases may also be provided.

In the Method section:

Author used various software such as Accelrys Draw 4.1 software, Accelrys Discovery Studio 4.1 software, Molecular Operating Environment (MOE) software. However, why particularly was this software used? Information is missing. The importance of using each of these softwares used for the present study may be provided.

\section{In the Results section:}

The statement "Analysis of the secondary structure of the target protein provided by Phyre revealed high confidence in the predicted structure" is unclear. It may be explained elaborately. How did the author arrive for a high confidence state in the predicted structure and what about a low confidence state? What are the criteria of a high confidence state? The analysis of results with respect to the figure may be explained elaborately.

Also, the analysis ProQ2 quality assessment may be provided. Based on this analysis how the protein quality is decided to be good. Ref for ProQ2 quality assessment may also be provided.

Further, the in silico molecular docking study using MOE software resulted in the successful 
docking. What are the criteria of successful docking? How has a successful docking state has been resulted? Also, why has naproxen been used as standard? What is the other standard recommended to be used in general in RA?

The in-silico validation could have been done for better results.

In the discussion section:

The results could have been discussed more elaborately for better impact.

It is not clear from the study why only one ligand is targeted. Other ligands could have been also studied and comparative analysis could have been provided.

Why and how astragalin is specifically targeted to inhibit C-C motif chemokine ligand 28 only?

The conclusion of the study could have been stronger:

The ref may be provided for the following lines:

"The CCL28 protein is involved in the angiogenesis of rheumatoid arthritis as it recruits leukocytes to the site of joint inflammation".

"In a few patients, serious liver damage due to methotrexate has been observed".

"Astragalin isolated from the leaves of black and green tea ..... activities".

"Methotrexate and leflunomide are DMARDs used for rheumatoid arthritis treatment".

Is the work clearly and accurately presented and does it cite the current literature?

Yes

Is the study design appropriate and is the work technically sound?

Yes

Are sufficient details of methods and analysis provided to allow replication by others? Partly

If applicable, is the statistical analysis and its interpretation appropriate?

Not applicable

Are all the source data underlying the results available to ensure full reproducibility? Partly

Are the conclusions drawn adequately supported by the results?

Partly

Competing Interests: No competing interests were disclosed.

Reviewer Expertise: Proteomics, immune proteomics, bioinformatics, metabolomics, arthritis, Coronary artery disease

I confirm that I have read this submission and believe that I have an appropriate level of 
expertise to confirm that it is of an acceptable scientific standard, however I have significant reservations, as outlined above.

Reviewer Report 22 July 2019

https://doi.org/10.5256/f1000research.20293.r50253

(c) 2019 UI Haq I. This is an open access peer review report distributed under the terms of the Creative Commons Attribution License, which permits unrestricted use, distribution, and reproduction in any medium, provided the original work is properly cited.

\section{Ihsan UI Haq}

Department of Pharmacy, Faculty of Biological Sciences, Quaid-i-Azam University, Islamabad, Pakistan

Is the work clearly and accurately presented and does it cite the current literature? Yes, the current work is accurately presented including the recent literature. Authors have discussed about the recent updates and potential application of Astragalin. The role of C-C motif chemokine ligand 28 (CCL28) has been cited explaining the recruitment of leukocytes and other proinflammatory factors at the site of joint inflammation and arthritis.

Is the study design appropriate and is the work technically sound?

Yes, authors have designed in silico study properly and focused on computational evaluation of astragalin as inhibitor of CCL28 for treatment of rheumatoid arthritis.

Are sufficient details of methods and analysis provided to allow replication by others? Yes, the detail has been provided to replicate the steps of study. The quality valuation of CCL28 was estimated and Molecular Operating Environment software was used for binding affinity analysis. Along with astragalin, naproxen was used as standard drug.

If applicable, is the statistical analysis and its interpretation appropriate? Not applicable

Are all the source data underlying the results available to ensure full reproducibility? Yes, the source data underlying the results are available.

Are the conclusions drawn adequately supported by the results?

Yes, the conclusion is supported by the results revealing that astragalin could have potential to serve as inhibitor of CCL28 for the treatment of rheumatoid arthritis. Binding energy of astragalin with its target is $-5.40 \mathrm{kcal} / \mathrm{mol}$ is very low in comparison to standard naproxen which has -4.87 $\mathrm{kcal} / \mathrm{mol}$ binding energy. Docking results proved that astragalin can act as potential inhibitor for CCL28 enzyme.

However, some minor comments are recommended.

1. Add some pharmacological aspects of astragalin in "Introduction" section.

2. Better to combine Figure 5 and 6 . 
3. Improve the resolution of the figures.

4. Proof reading is required.

Is the work clearly and accurately presented and does it cite the current literature? Yes

Is the study design appropriate and is the work technically sound?

Yes

Are sufficient details of methods and analysis provided to allow replication by others? Yes

If applicable, is the statistical analysis and its interpretation appropriate?

Not applicable

Are all the source data underlying the results available to ensure full reproducibility? Yes

Are the conclusions drawn adequately supported by the results?

Yes

Competing Interests: No competing interests were disclosed.

Reviewer Expertise: Pharmaceutical Sciences, Biochemistry.

I confirm that I have read this submission and believe that I have an appropriate level of expertise to confirm that it is of an acceptable scientific standard. 
The benefits of publishing with F1000Research:

- Your article is published within days, with no editorial bias

- You can publish traditional articles, null/negative results, case reports, data notes and more

- The peer review process is transparent and collaborative

- Your article is indexed in PubMed after passing peer review

- Dedicated customer support at every stage

For pre-submission enquiries, contact research@f1000.com 